\title{
O (DES)FINANCIAMENTO DO DIREITO À SAÚDE NO BRASIL: UMA REFLEXÃO NECESSÁRIA
}

\author{
Jarbas Ricardo Almeida Cunha ${ }^{1}$
}

Resumo: este artigo busca guiar o leitor no caminho normativo do (des)financiamento do direito à saúde no Brasil, desde a promulgação da Constituição da República de 1988 até a aprovação da Emenda Constitucional no 95, de 2016, que instituiu um novo regime fiscal. Para atingir esse desiderato, utiliza-se a metodologia de revisão de literatura de tipo narrativa, comparando estudos científicos que lidam com a temática suscitada. $\mathrm{O}$ resultado a que chegamos demonstra que o direito à saúde - já subfinanciado desde seu nascedouro - passa por um processo de desfinanciamento estrutural, abalando os alicerces de nossa Constituição Cidadã.

Palavras-chave: Financiamento; Direito à Saúde; Constituição Federal

\section{THE (UN) FINANCING OF THE RIGHT TO HEALTH IN BRAZIL: A NECESSARY REFLECTION}

Abstract: this article seeks to guide the reader on the normative path of the (de) financing of the right to health in Brazil, from the promulgation of the 1988 Constitution to the approval of Constitutional Amendment $n^{\circ}$ 95, of 2016, which instituted a new tax regime. To achieve this goal, we use the narrative-type literature review methodology, comparing scientific studies that deal with the theme raised. The result we have achieved shows that the right to health - already underfunded since its birth - it goes through a process of structural de-financing, shaking the foundations of our Citizen Constitution.

Keywords: Financing; Right to Health; Federal Constitution

\section{Introdução}

Este artigo objetiva analisar o constructo normativo de desfinanciamento do direito à saúde no Brasil, desde a constitucionalização do Sistema Único de Saúde (SUS) em 1988 com o advento do Orçamento da Seguridade Social (OSS) até a vigência da Emenda Constitucional n 95, de 2016 (“Emenda do Teto dos Gastos”).

A metodologia apresentada para atingir o objetivo pretendido é a revisão de literatura de tipo narrativa, emque se cogita descrever o "estado da arte" de determinado assunto, constituindo-se, basicamente, em utilização de artigos científicos, livros, teses, dissertações e outros instrumentos qualitativos de consulta sobre a questão a ser aprofundada (ROTHER, 2007).

Urge importante debater o histórico normativo que resultou em processo de

\footnotetext{
${ }^{1}$ Doutor em Direito, Estado e Constituição pela Universidade de Brasília (UnB). Especialista em Direito Sanitário pela Fundação Oswaldo Cruz (Fiocruz). Núcleo de Saúde - DPU. jarbas.ricardo@ yahoo.com.br
} 
desfinanciamento do direito à saúde no Brasil, ocasionando problemas estruturais na política pública de saúde via SUS, principalmente em um contexto de grave pandemia que atinge nosso país de forma trágica.

\section{1-Histórico normativo do (des)financiamento do direito à saúde no Brasil}

Com a promulgação da Constituição da República Federativa do Brasil de 1988, a saúde passou a integrar a Seguridade Social (art.194), juntamente com a previdência e a assistência social, devendo ser financiada por recursos da União, dos estados, do Distrito Federal e dos municípios, além das contribuições sociais (art.195). Neste ponto inicial da discussão, que envolve a formação da seguridade social, o primeiro destaque surge com o art. 55 do Ato das Disposições Constitucionais Transitórias (ADCT) da Constituição, que implementa - de forma inédita em nossa história constitucional - o percentual do Orçamento da Seguridade Social (OSS) a ser investido na política pública de saúde:

Art. 55. Até que seja aprovada a lei de diretrizes orçamentárias, trinta por cento, no mínimo, do orçamento da seguridade social, excluído o seguro-desemprego, serão destinados ao setor de saúde $(\mathrm{CF} / 88$, grifo nosso).

Esse artigo constitucional do ADCT não chegou a ser efetivado em nosso país, prejudicando a estabilidade inicial do financiamento da saúde nos incipientes momentos da Nova República pós-Constituição. O percentual estipulado - 30\% (trinta por cento) não foi cumprido nos anos de 1990 e 1991, e no ano de 1992 ele só foi cumprido porque foram contabilizados como ações de saúde os gastos em recursos humanos, merenda escolar, obras urbanas, dentre outros, descaracterizando, dessa forma, o artigo em tela, já que esses gastos contabilizados não estavam no rol de ações e serviços em saúde elencados pela Constituição Cidadã (SERVO et al., 2011).

No ano de 1993, a disputa entre os recursos da Saúde e da Previdência - prevista por estudiosos como Menicucci (2009) e Vianna (2005) pela justificativa de uma crise previdenciária - acirrou-se, resultando no fim da solidariedade das contribuições previdenciárias para o orçamento da saúde. Tal desenrolar dos fatos gerou, inclusive, empréstimos do Fundo de Amparo ao Trabalhador (FAT) ao Ministério da Saúde (MS), situação que deixou patente que o financiamento da saúde necessitava de um imposto específico sobre a matéria ${ }^{1}$ (SERVO et al., 2011). 
Sendo assim, recorremos novamente ao ADCT da Constituição para analisarmos o imposto específico e provisório criado para aumentar os recursos financeiros para a saúde, a Contribuição Provisória sobre Movimentação Financeira (CPMF), conforme Emenda Constitucional (EC) $\mathrm{n}^{\mathrm{o}} 12 / 1996^{2}$ :

Art. 74 - A União poderá instituir contribuição provisória sobre movimentação ou transmissão de valores e de créditos e direitos de natureza financeira.

$\S 3^{\circ}$ - O produto da arrecadação da contribuição de que trata este artigo será destinado integralmente ao Fundo Nacional de Saúde, para financiamento das ações e serviços de saúde $(\mathrm{CF} / 88$, grifo nosso).

Ao contrário do que supõe o senso comum, as contribuições sociais como $\mathrm{COFINS}^{3}, \mathrm{CSLL}^{4}$ e $\mathrm{CPMF}^{5}$ foram responsáveis por uma média de incríveis $70 \%$ (setenta

\footnotetext{
${ }^{1}$ No ano de 1993 o percentual repassado para o Ministério da Saúde foi o equivalente a 15,5\% da receita de contribuições, metade do previsto, esse problema alertou para que fosse apresentada a Proposta de Emenda Constitucional (PEC) $\mathrm{n}^{\circ} 169$, que estabelecia como fonte específica de financiamento federal da saúde 30\% do Orçamento da Seguridade Social (OSS) da União e mais 10\% das Receitas de Impostos de competência federal. Essa PEC teve um período de tramitação de sete anos no Congresso Nacional e foi promulgada originando a Emenda Constitucional $(E C) n^{\circ} 29$, de 2000, que regula a aplicação de cada ente federado, porém, o texto aprovado não contemplou essa regra de cálculo de aplicação mínima federal em ações e serviços públicos de saúde (ASPS) nos seus 10\% propostos (FUNCIA, 2018).

${ }^{2}$ Com a EC 21/1999 os recursos da CPMF - que antes eram exclusivamente para a saúde - foram compartilhados entre a Previdência e o Fundo de Combate à Pobreza com aumento da alíquota de 0,20 para $0,38 \%$ (depois estabilizado em 0,30 ).

${ }^{3}$ Contribuição para o Financiamento da Seguridade Social.

${ }_{5}^{4}$ Contribuição Social sobre o Lucro Líquido.

${ }^{5}$ A CPMF era uma contribuição destinada integralmente para o custeio da política pública de saúde, da previdência social e do Fundo de Combate e Erradicação da Pobreza. O histórico da destinação de seus recursos pode ser sintetizado da seguinte forma: conforme art. ${ }^{\circ} 18$ da Lei ${ }^{\circ} 9.311$, de 1996, a totalidade da arrecadação era destinada para o Fundo Nacional de Saúde (FNS). Três anos depois, em 1999, com a aprovação da Emenda Constitucional n ${ }^{\circ}$ 21, os recursos orçamentários da CPMF eram transferidos também para a Previdência Social e para o combate à pobreza, 26\% da arrecadação iam para a primeira, enquanto $21 \%$ eram direcionados para o segundo; o restante era destinado ao FNS (MARQUES; PIOLA; ROA, 2016).
}

por cento) do financiamento da saúde no período de 1997 até 2007, sendo que a CPMF sozinha era responsável por 1/3 (um terço) desses recursos, logrando a estabilização momentânea dos recursos destinados às ações e serviços da política pública de saúde (ASPS), conforme Gráfico 1 a seguir (PIOLA et al., 2013):

\author{
Gráfico 1 - Ministério da Saúde (MS): execução do gasto total por fonte \\ de recursos, CPMF e demais fontes $(1995$ - 2011)
}




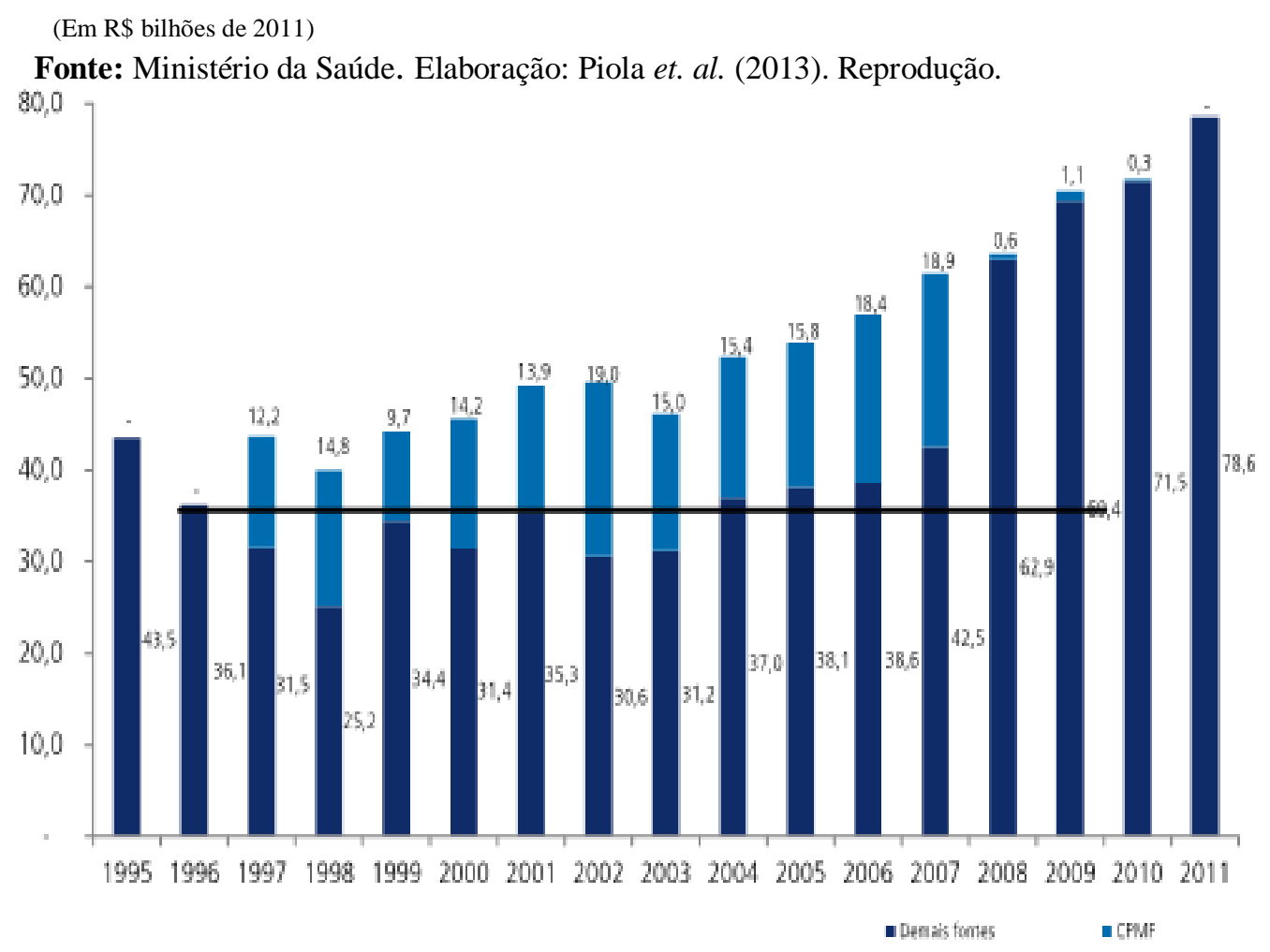

Mas a CPMF, por ter suscitado uma discussão sobre sua provisoriedade, sempre foi alvo de polêmicas em torno da carga tributária e sobre sua efetividade na aplicação dos recursos. A CPMF, na visão de Salvador (2007), "é um desses tributos regressivos, pois ao incidir ao longo da cadeia produtiva, é passível de ser transferida a terceiros; em outras palavras, para os preços dos produtos adquiridos pelos consumidores" ${ }^{\text {. }}$. Evidenciase aí, mais uma vez, a injusta tributação brasileira, caracterizada pelo fato de que quem mais financia o SUS são as classes menos favorecidas, principalmente por meio do consumo.

Nos dez anos de sua vigência, a CPMF também sofreu a ingerência da Desvinculação de Receitas da União (DRU), instrumento inaugurado pelos governos

\footnotetext{
${ }^{6}$ Disponível em: http://diplo.org.br/2007-11,a2008. Acesso em: 12 jul. 2021.
} 
brasileiros da década de 1990, depois dos acordos com o Fundo Monetário Internacional (FMI) que vigoraram por muito tempo e, que, agora, têm sido novamente incorporados ao debate governamental. No caso específico da CPMF, de 1997 a 2006, 18\% (dezoito por cento) da arrecadação deste tributo foram desviados via DRU para serem utilizados na rubrica de "restos a pagar", estes geral e invariavelmente utilizados para pagamento da dívida e consequente valorização do capital financeiro majoritariamente internacional (SALVADOR, 2010).

A DRU, concomitantemente à criação da CPMF, foi institucionalizada no Brasil com a denominação de Fundo Social de Emergência (FSE) - posteriormente reeditado como Fundo de Estabilização Fiscal (FEF) -, o qual foi transformado no ano de 2000 em Desvinculação de Receitas da União (DRU), cujo objetivo era desvincular 20\% (vinte por cento) - atualmente são $30 \%$ (trinta por cento) ${ }^{7}$ - das contribuições sociais, impactando as que financiam a seguridade social, para a formação de superávits primários anuais comprovadamente destinados para o pagamento de juros e amortização da dívida pública (SANTOS; FUNCIA, 2019).

Com a extinção da CPMF, em 2007, por pressão da oposição parlamentar ${ }^{8}$, o governo à época e o Movimento da Reforma Sanitária Brasileira (MRSB) reiniciaram a discussão sobre a regulamentação da Emenda Constitucional (EC) 29/2000, que assegurava a participação dos três níveis de Governo no financiamento do SUS a partir da definição de um percentual mínimo de recursos por ano ${ }^{9}$. Afinal, a abolição da

\footnotetext{
${ }^{7}$ Conforme Emenda Constitucional no ${ }^{\circ}$ 93, de 8 de setembro de 2016, com a seguinte ementa: "Altera o Ato das Disposições Constitucionais Transitórias para prorrogar a desvinculação de receitas da União e estabelecer a desvinculação de receitas dos Estados, Distrito Federal e Municípios". Disponível em: http://www.planalto.gov.br/ccivil_03/constituicao/Emendas/Emc/emc93.htm. Acesso em: 12 jul. 2021.

${ }^{8}$ O Senado Federal brasileiro, na madrugada de 13 de dezembro de 2007, rejeitou a proposta de prorrogação da CPMF (PEC 89/2007) até o exercício financeiro de 2011 por uma diferença de apenas 4 (quatro) votos (o Governo, pró-CPMF, obteve 45 votos e precisaria de 49) sob a justificativa genérica de que a carga tributária no Brasil já era alta demais para suportar mais esse fardo. Tal alegação, além de ser uma inverdade, é incompatível com a atividade legislativa do Senado, pois este, segundo Monteiro (2008), no mesmo período legislativo revalidou a DRU, aprovou o aumento de outros impostos - Imposto sobre Operações Financeiras (IOF), operações de crédito e da Contribuição Social sobre o Lucro Líquido (CSLL), além de promover cortes na despesa pública. Conferir também em: https://www12.senado.leg.br/noticias/materias/2007/12/13/sete-horas-de-intenso-debate-para-votar-acpmf. Acesso em: 12 jul. 2021.

${ }^{9}$ De acordo com o art. 198, $\S 3^{\circ}$, Inc. II, da CF/88: Art. 198. As ações e serviços públicos de saúde integram uma rede regionalizada e hierarquizada e constituem um sistema único, organizado de acordo com as seguintes diretrizes:

(...)

$\S 3^{\circ}$ Lei complementar, que será reavaliada pelo menos a cada cinco anos, estabelecerá:

(...)
} 
II - os critérios de rateio dos recursos da União vinculados à saúde destinados aos Estados, ao Distrito Federal e aos Municípios, e dos Estados destinados a seus respectivos Municípios, objetivando a progressiva redução das disparidades regionais (grifo nosso).

estabilizadora CPMF levou à necessidade de se pensar em um instrumento capaz de substituí-la.

A regulamentação exigida por meio da EC 29/2000 através do art. 198, §3º, da Constituição Federal, foi finalmente publicada pela Lei Complementar $n^{\circ} 141$, de 13 de janeiro de $2012^{10}$, que consolidou os investimentos em saúde pela União, estados, Distrito Federal e municípios. Os estados continuaram obrigados a investir, no mínimo, $12 \%$ (doze por cento) da arrecadação dos impostos, enquanto os municípios, 15\% (quinze por cento); já o Distrito Federal investiria de 12 a 15\% (doze a quinze por cento), conforme a classificação da fonte da receita em estadual ou distrital ${ }^{11}$.

Segundo Funcia (2018), os impactos da aprovação da Lei Complementar que regulamenta o percentual de investimento de cada ente público nas Ações e Serviços Públicos de Saúde (ASPS) apresentam um balanço contraditório. Se, por um lado, a aprovação ratificou normativos da Lei Orgânica da Saúde (LOS) formada pelas leis $n^{\circ}$ 8.080 e $\mathrm{n}^{\circ} 8.142$, ambas de 1990 , por outro lado, não efetivou o investimento de $10 \%$ da receita corrente bruta $(\mathrm{RCB})$ pela União, uma demanda dos sanitaristas apresentada por meio de projeto de iniciativa popular com mais de 2 milhões de assinaturas ${ }^{12}$.

Sobre o financiamento do SUS na especificidade da análise de suas fontes apresentando como parâmetro o Fundo Nacional de Saúde (FNS) administrado pelo Ministério da Saúde (MS) -, podemos destacar que a maioria dos recursos é proveniente de contribuições sociais, aumentando de $66,2 \%$ (sessenta e seis vírgula dois por cento) do total das fontes, no ano de 1996, para consideráveis $89,8 \%$ (oitenta e nove vírgula oito por cento) no ano de 2015, sendo que o maior índice foi atingido no ano de 2013, quando chegou a incríveis $94,6 \%$ (noventa e quatro vírgula seis por cento).

As principais contribuições sociais no financiamento da política pública de saúde no Brasil são a Contribuição para o Financiamento da Seguridade Social (Cofins), a

\footnotetext{
${ }_{10}$ Disponível em: http://www.planalto.gov.br/ccivil_03/leis/LCP/Lcp141.htm. Acesso em: 12 jul. 2021.

${ }^{11}$ Uma observação importante é que a Lei Complementar 141/2012 que regulamentou a EC 29 não prevê punição para os entes federativos que não cumprirem os investimentos estipulados.

12 Por iniciativa do CNS, juntamente com os respectivos Conselhos Estaduais e Municipais de Saúde, entidades representativas de variados segmentos da sociedade civil e movimentos sociais e populares do campo sanitário, foi articulado o "Movimento Saúde+10" com o objetivo de aprovar via processo legislativo uma aplicação mínima federal em ações e serviços públicos de saúde de 10\% das Receitas Correntes Brutas (RCB), já que esta demanda havia sido excluída da Lei Complementar 141, de 2012.
} 
Sendo assim, entre 2013 e 2015, os ativistas do "Saúde+10" participaram de várias atividades de mobilização com prefeitos, governadores e parlamentares com o intuito de aprovar o PLP 321, de 2013, que abarcava esse "piso" federal para o SUS. O resultado se mostrou infrutífero, sendo que o Congresso promulgou a Emenda Constitucional (EC) $\mathrm{n}^{\circ}$ 86, de 2015, que agravou o processo de subfinanciamento crônico do SUS ao delimitar um investimento de $15 \%$ da receita corrente líquida (RCL) pela União (SANTOS; FUNCIA, 2019).

Contribuição sobre o Lucro Líquido de Empresas (CSLL) e, enquanto esteve em vigor, a Contribuição Provisória sobre Movimentação Financeira (CPMF). Essas três contribuições sociais, como já mencionamos, foram responsáveis na década compreendida entre 1997 e 2007 por 70\% (setenta por cento) do orçamento do SUS (MARQUES, 2017).

Sobre a participação dos entes públicos no financiamento da política de saúde, observa-se a influência da aprovação da EC 29/2000 combinada com a Lei Complementar $141 / 2012$, as quais promoveram, dessa forma, a descentralização dos recursos investidos via União e o consequente aumento de participação dos estados e, principalmente, dos municípios no total do gasto público em saúde.

Segundo Mendes e Funcia (2016), em 1980, portanto, bem antes da constitucionalização do SUS, a União financiava $75 \%$ (setenta e cinco por cento) dos recursos em saúde; uma década depois (1990), sua participação no financiamento do incipiente SUS se manteve estável em 74,4\% (setenta e quatro vírgula quatro por cento) do total, sendo que os estados participavam com 13,5\% (treze e meio por cento) e os municípios com $12,1 \%$ (doze vírgula um por cento).

Na década seguinte, quando da aprovação da EC 29/2000, a participação da União decresceu para 59,98\% (cinquenta e nove vírgula noventa e oito por cento) do total, enquanto a dos estados aumentou para 18,5\% (dezoito e meio por cento) e a dos municípios para $21,7 \%$ (vinte e um vírgula sete por cento). Com a consolidação da regulamentação da EC 29 por meio da Lei Complementar n ${ }^{\circ} 141$, a participação do governo federal no financiamento do SUS diminuiu para 43,2\% (quarenta e três vírgula dois por cento) no ano de 2015.

Já no período abrangido entre 2000 e 2015, assinala-se o significativo crescimento da participação dos estados de $18,5 \%$ (dezoito e meio por cento) para $25,9 \%$ (vinte e cinco vírgula nove por cento), enquanto a participação dos municípios elevou-se de $21,7 \%$ (vinte e um vírgula sete por cento) para 30,9\% (trinta vírgula nove por cento) (MARQUES, 2017).

O Gráfico 2, o Gráfico 3 e a Figura 1 abaixo atualizam a mudança estrutural do 
financiamento federativo e o respectivo investimento de cada ente na política pública de saúde, reflexo da aprovação da EC 29/2000 e da LC 141/2012.

Gráfico 2 - Financiamento Federativo: mudança estrutural

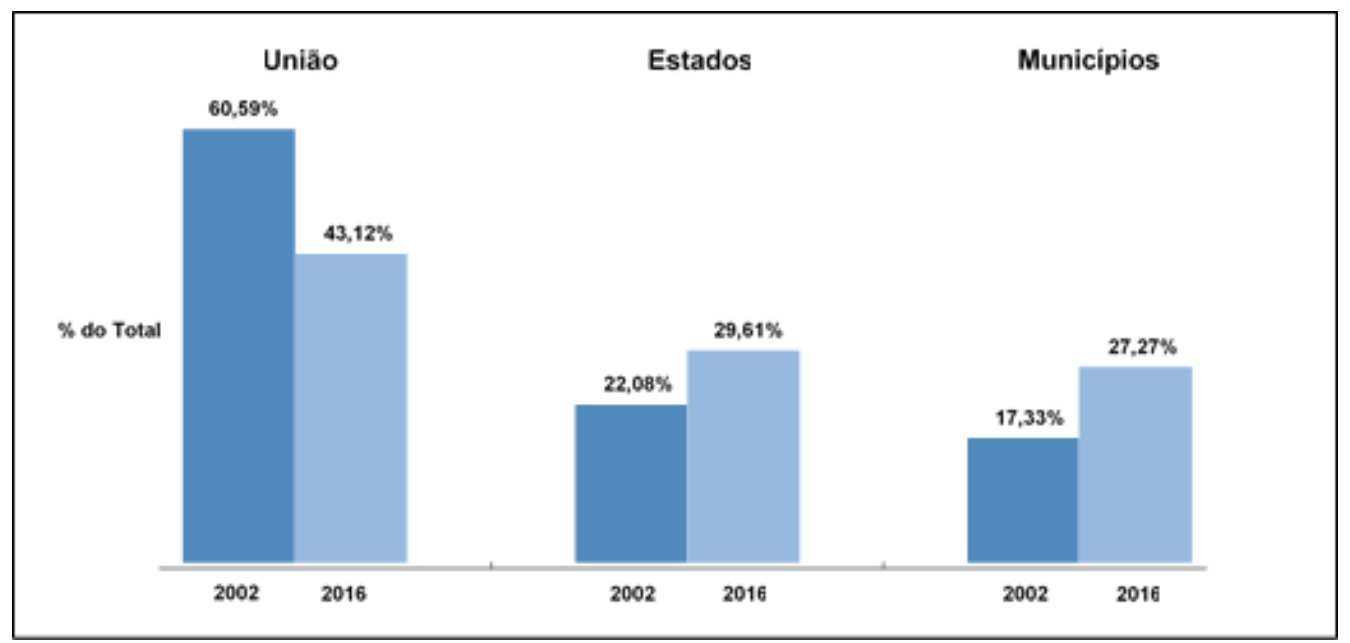

Fonte: BSPN e Siga Brasil. Elaboração própria a partir de Afonso (2017).

Gráfico 3 - Composição do gasto público com saúde por esfera de governo 2003-2015, \% do total

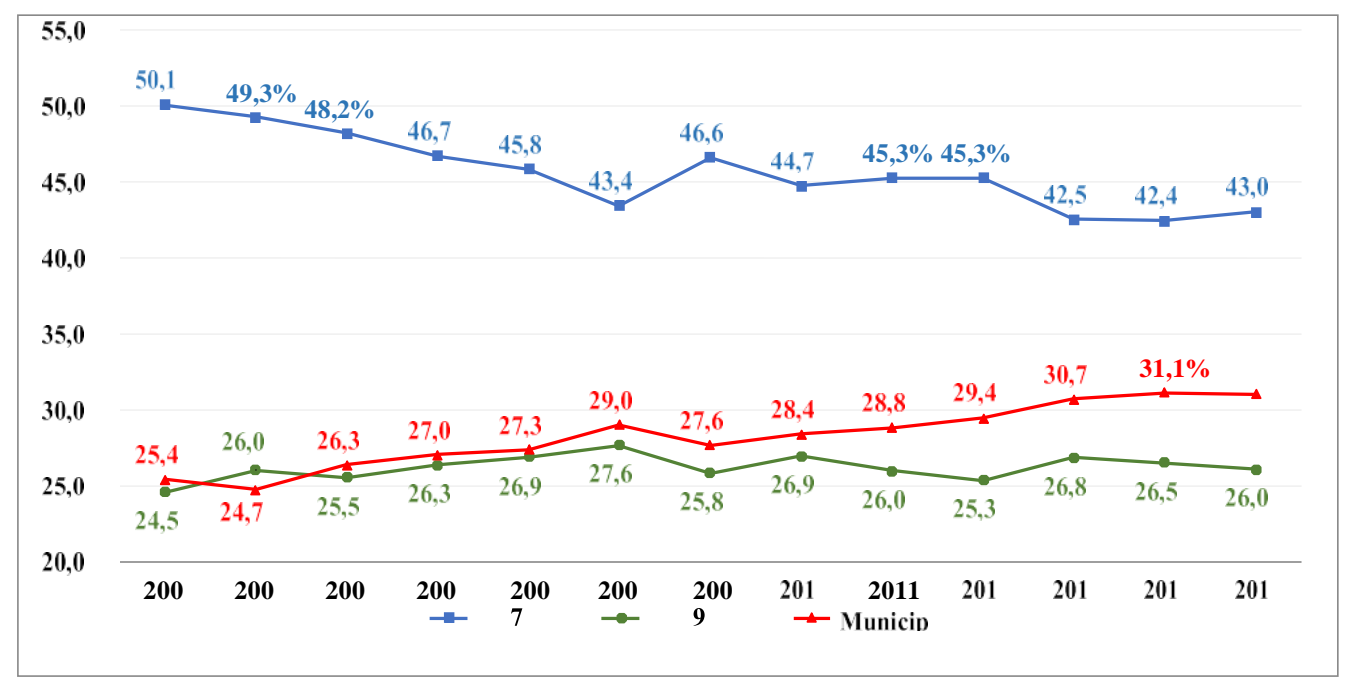

Fonte: Ministério da Saúde e SIOPS. Elaboração: Vieira; Benevides (2016) em Nota Técnica do IPEA (2016). Reprodução. 
Figura 1 - Aplicação de Recursos em Ações e Serviços de Políticas de Saúde - ASPS pelos entes da Federação

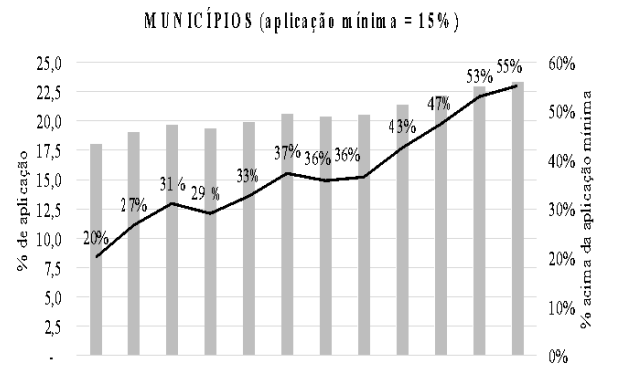

200420052006200720082009201020112012201320142015 \%de aplicą̧o - Aplicą̧o acima domínimo

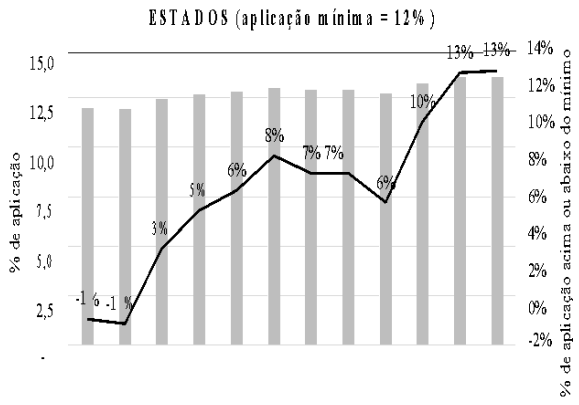

200420152006200720082009201020112012201320142015

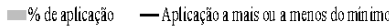

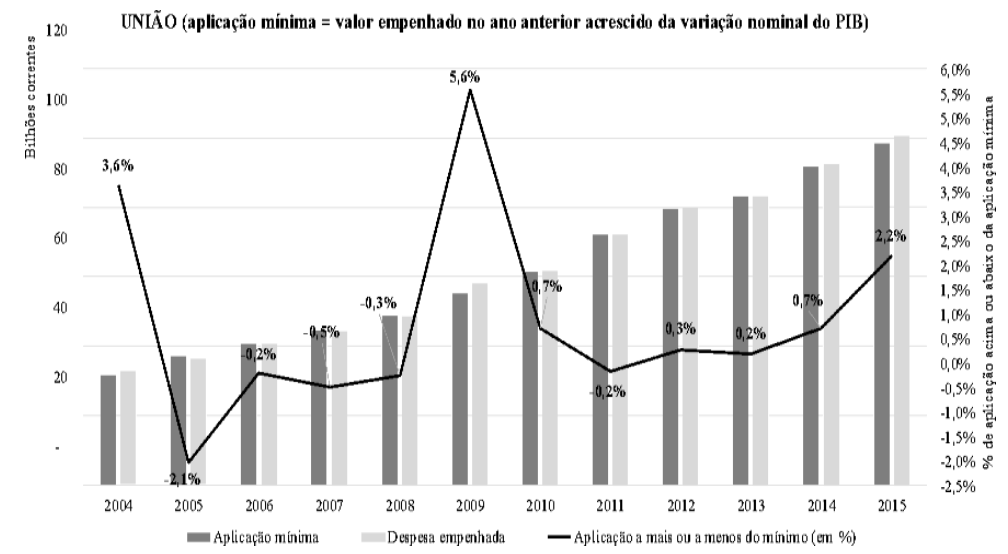

Fonte: Siga Brasil. Elaboração: Vieira; Benevides (2016). Reprodução.

Segundo Mendes e Funcia (2016), apesar do avanço representado pelo aumento da participação dos entes no financiamento da saúde incentivados pela vigência da EC 29/2000 e da LC 141/2012, o investimento poderia ser ainda maior caso os estados e a União tivessem aplicados recursos legalmente adequados:

(...) o volume de recursos poderia ter sido mais elevado se o governo federal e os Estados tivessem cumprido a EC/29 de maneira plena, sem utilizar de diferentes mecanismos que reduziram a alocação de recursos decorrente de interpretações no mínimo questionáveis sobre critérios estabelecidos pela Emenda. Diferentemente dos Municípios, cuja aplicação efetiva está muito acima do mínimo de $15 \%$ exigido, as esferas nacional e estadual de governo aplicaram muito próximo do parâmetro mínimo constitucional, o que parecia indicar que consideravam esse parâmetro não como um 'piso', mas sim um 'teto' de aplicação (MENDES; FUNCIA, 2016, p. 155, grifo nosso). 
Destacamos também que o Brasil - de acordo com dados de várias instituições e organismos ${ }^{13}$ - é o único país do mundo de sistema universal onde os investimentos privados superam os investimentos públicos. Dados do Instituto Brasileiro de Geografia e Estatística (IBGE) (2012) estimam que o investimento total em saúde no Brasil - tanto público quanto privado - é de aproximadamente $8,4 \%$ (oito vírgula quatro por cento) do Produto Interno Bruto (PIB) do país, ficando abaixo dos Estados Unidos, que investem 15\% (quinze por cento), mas mais próximo dos países membros da Organização para Cooperação e Desenvolvimento Econômico (OCDE) que possuem sistema universal, como Inglaterra $(8,4 \%$ - oito vírgula quatro por cento), Espanha (8,5\% - oito vírgula cinco por cento), Austrália (8,98\% - oito vírgula noventa e oito por cento) e Canadá (10,1\% - dez vírgula um por cento).

O problema de fundo do financiamento da saúde no Brasil é que o investimento público é bem abaixo do privado; enquanto o primeiro está em torno de $45 \%$ (quarenta e cinco por cento), o segundo alcança $55 \%^{14}$ (cinquenta e cinco por cento), fato absurdamente inédito em país com sistema universal de saúde e que se apresenta como uma das dez maiores economias do mundo ${ }^{15}$ (OMS, 2012).

Para agravar essa situação, segundo Ocké-Reis (2018), o gasto tributário em saúde no país, ou seja, a renúncia de arrecadação fiscal, corresponde a um montante bastante significativo. No período entre 2003 e 2015 - no somatório desses 12 anos - o governo subsidiou o setor privado de saúde, por meio do instituto da renúncia de arrecadação de tributos, em algo em torno de $\mathrm{R} \$ 331,5$ bilhões de reais. Um crescimento da renúncia fiscal sanitária de $\mathrm{R}$ \$ 6,1 bilhões em 2003 para $\mathrm{R}$ \$ 12,5 bilhões em 2015, valor este que poderia ampliar a alocação de recursos financeiros na atenção primária e nos bens e serviços de média e alta complexidade tecnológica.

Segundo Santos e Funcia (2019), o investimento público consolidado pelos entes federativos - União, estados, DF e municípios - está estabilizado em 4\% (quatro por cento) do Produto Interno Bruto (PIB) ${ }^{16}$, o que significa a metade do que é investido, por

\footnotetext{
${ }_{13}$ Organização Mundial da Saúde (OMS, 2012), Instituto de Pesquisa Econômica e Aplicada (IPEA, 2013), Instituto Brasileiro de Geografia e Estatística (IBGE, 2012).

${ }^{14} \mathrm{O}$ investimento privado é bancado majoritariamente pelo consumo das famílias, o que é preocupante em uma conjuntura de crise econômica, além de contar com fartas desonerações e isenções fiscais do Estado.

${ }^{15}$ A título de comparação com países de sistema universal de saúde, a Austrália tem investimento público de 67\% e a Inglaterra de 87\% (OMS, 2012).

${ }^{16}$ Segundo estudo do Tesouro Nacional intitulado Aspectos Fiscais da Saúde no Brasil, o investimento
} 
público em saúde no ano de 2018 foi de $3,8 \%$ do PIB. Disponível em: https://www.tesouro.fazenda.gov.br/documents/10180/318974/AspectosFiscaisSa\%C3\%BAde2018/a720 3af9-2830-4ecb-bbb9-4b04c45287b4. Acesso em: 12 jul. 2021.

exemplo, no sistema universal de saúde do Reino Unido - em torno de $8 \%$ (oito por cento)

(OMS, 2019).

2- A Emenda Constitucional n⿳ 95/2016: impactos do "teto de gastos" sobre o direito à saúde

Depois de analisarmos o subfinanciamento crônico da política pública de saúde, desde sua constitucionalização em 1988 até o início da segunda década dos anos 2000, com a vigência da Emenda Constitucional 29/2000 e a Lei Complementar 141/2012, analisaremos as consequências da promulgação da Emenda Constitucional no 95, de 2016. Esta implantou no Brasil um Novo Regime Fiscal (NRF) baseado no congelamento dos gastos públicos, atingindo de modo especial a política pública de saúde e produzindo o que economistas (FUNCIA, 2019; OCKÉ REIS, 2018) denominam como a era da transição do subfinanciamento para o desfinanciamento do SUS em nosso país.

A Emenda Constitucional (EC) $n^{\circ}$ 95, de 15 de dezembro de 2016, de iniciativa do executivo federal e tramitada como Proposta de Emenda Constitucional (PEC) $n^{\circ} 241$ na Câmara dos Deputados e como PEC no 55 no Senado Federal, foi aprovada em 2016 com a seguinte ementa: “Altera o Ato das Disposições Constitucionais Transitórias, para instituir o Novo Regime Fiscal, e dá outras providências"17.

A EC 95/2016 acrescentou 9 (nove) artigos ao ADCT da Constituição Federal ${ }^{18}$, aprovando um congelamento do investimento público - limitação por meio de um teto de gastos das despesas primárias - que vigorará por vinte exercícios financeiros, isto é, de 2016 a 2036. Tal cenário tem impacto direto nas funções do executivo, legislativo e judiciário, além dos reflexos nos entes subnacionais - estados e municípios, e também em políticas públicas essenciais para o desenvolvimento do país, como saúde e educação.

Como relatam Vieira e Benevides (2016), há uma proposta de reforma do Estado por meio da EC 95/2016 ao desfinanciar as estratégicas políticas públicas constitucionalizadas da saúde e educação:

Trata-se, portanto, de uma reforma implícita do Estado: a EC 95 dá corpo ao "Novo Regime Fiscal" (NRF), sem revelar a real intenção de reduzir a participação das despesas primárias em relação ao Produto Interno Bruto (PIB), implicando a redução da participação do Estado em diversas políticas públicas, entre as quais as de saúde e de educação. 
Não é por outra razão que a proposta do NRF surge como emenda

${ }^{17}$ Disponível em: http://www.planalto.gov.br/ccivil_03/constituicao/emendas/emc/emc95.htm. Acesso em: 12 jul. 2021.

18 De acordo com o art. $1^{\circ}$ da EC 95/2016: “O Ato das Disposições Constitucionais Transitórias passa a vigorar acrescido dos seguintes arts. 106,107, 108, 109, 110, 111, 112, 113 e 114”.

à constituição, dado que essas duas políticas têm percentuais garantidos de receitas definidos na CF 1988. Ou seja, se a intenção da EC 95 não fosse reduzir a participação das despesas com saúde e educação em proporção do PIB, tal reforma não necessitaria ser inscrita na Constituição (VIEIRA; BENEVIDES, 2016, p. 3, grifo nosso).

Funcia (2018) entende que a aprovação da EC 95/2016 serve para lastrear duas diretrizes básicas: a primeira sintetizada pela insígnia "A Constituição não cabe no orçamento", sob a justificativa de que a concretização das políticas públicas seria a grande culpada pela ocorrência de déficits no orçamento federal devendo-se então reduzir as despesas primárias pelo mecanismo da austeridade fiscal. A segunda - relacionada intrinsecamente com a primeira - seria viabilizar a formação de superávits primários por vinte exercícios financeiros (2016-2036), para o devido pagamento de juros e amortização da dívida pública, sendo que este pagamento não sofreria qualquer limite.

Atualmente, aguardam julgamento no STF sete Ações Diretas de Inconstitucionalidades (ADINs) ${ }^{19}$, objetivando a declaração de inconstitucionalidade da Emenda Constitucional $n^{\circ} 95$ por explícita violação aos mandamentos constitucionais, inclusive às suas cláusulas pétreas. A petição inicial acostada na ADI $n^{\circ} 5715$, que foi protocolada no STF em 2017, resumiu em um quadro as seguintes violações constitucionais:

\section{Quadro 1 - Violações Constitucionais da EC 95/2016}

\begin{tabular}{|l|l|}
\hline \multicolumn{1}{|c|}{ Constituição Federal } & \multicolumn{1}{|c|}{ Violação } \\
\hline $\begin{array}{l}\text { Art. 60. A Constituição poderá ser } \\
\text { emendada mediante proposta: }\end{array}$ & $\begin{array}{l}\text { Viola limites materiais implícitos ao } \\
\text { romper com a identidade } \\
\text { constitucional, vocacionada à } \\
\text { efetivação de direitos sociais. }\end{array}$ \\
\hline
\end{tabular}




\begin{tabular}{|l|l|}
\hline $\begin{array}{l}\text { Art. 60. } \\
(\ldots)\end{array}$ & $\begin{array}{l}\text { Em tramitação no Senado Federal, não } \\
\text { foram respeitadas as regras regimentais }\end{array}$ \\
$\S 2^{\circ}$ - A proposta será discutida e votada & $\begin{array}{l}\text { relativas à regular discussão da matéria. } \\
\text { em cada Casa do Congresso Nacional, } \\
\text { em domenda Constitucional retira por }\end{array}$ \\
$\begin{array}{l}\text { aprovada te obtiver, em ambos, três } \\
\text { quintos dos votos dos respectivos } \\
\text { membros. }\end{array}$ & $\begin{array}{l}\text { cinco legislaturas a plenitude da } \\
\text { atuação dos representantes eleitos, uma } \\
\text { vez que estarão limitados na definição } \\
\text { de temas centrais da gestão financeira } \\
\text { d...) }\end{array}$ \\
$\begin{array}{l}\text { da União com reflexo direto em direitos } \\
\text { proposta de emenda tendente a abolir: }\end{array}$ & e garantias fundamentais: \\
\hline
\end{tabular}

${ }^{19}$ São elas: ADI 5633, ADI 5643, ADI 5655, ADI 5658, ADI 5680, ADI 5715 e ADI 5743.

\begin{tabular}{|c|c|}
\hline $\begin{array}{l}\text { II - o voto direto, secreto, universal e } \\
\text { periódico; }\end{array}$ & $\begin{array}{l}\text { "Art. 106. Fica instituído o Novo } \\
\text { Regime Fiscal no âmbito dos } \\
\text { Orçamentos Fiscal e da Seguridade } \\
\text { Social da União, que vigorará por vinte } \\
\text { exercícios financeiros, nos termos dos } \\
\text { arts. } 107 \text { a } 114 \text { deste Ato das } \\
\text { Disposições } \\
\text { Transitórias". }\end{array}$ \\
\hline III - a separação dos Poderes; & $\begin{array}{l}\text { A Emenda Constitucional, de iniciativa } \\
\text { do Poder Executivo, cria limitações ao } \\
\text { Poder Judiciário, portador de } \\
\text { autonomia financeira: } \\
\text { Art. 107. Ficam estabelecidos, para } \\
\text { cada exercício, limites individualizados } \\
\text { para as despesas primárias: } \\
\text { (...) } \\
\text { II - do Supremo Tribunal Federal, do } \\
\text { Superior Tribunal de Justiça, do } \\
\text { Conselho Nacional de Justiça, da } \\
\text { Justiça do Trabalho, da Justiça Federal, } \\
\text { da Justiça Militar da União, da Justiça } \\
\text { Eleitoral e da Justiça do Distrito Federal } \\
\text { e Territórios, no âmbito do Poder } \\
\text { Judiciário; }\end{array}$ \\
\hline IV - os direitos e garantias individuais. & $\begin{array}{l}\text { A Emenda Constitucional implica em } \\
\text { claro retrocesso na aplicação de } \\
\text { recursos que importam na garantia de } \\
\text { direitos fundamentais como saúde e } \\
\text { educação. }\end{array}$ \\
\hline
\end{tabular}

Fonte: ADI 5715. Disponível em: http://portal.stf.jus.br/processos/detalhe.asp?incidente=5203351. Acesso em: 12 jul. 2021.

A EC 95/2016 estabelece um teto para as despesas primárias do Executivo, Legislativo e Judiciário, sendo que esse teto orçamentário terá sua base fixada no valor 
das despesas pagas no exercício financeiro de 2016, data que marca o início da sua vigência. Do exercício financeiro do ano de 2016 até o exercício financeiro de 2036, ou seja, durante um período de 20 anos, o teto estipulado pela EC 95 será corrigido apenas pela inflação - utilizando como referência o Índice de Preços ao Consumidor Amplo (IPCA) - do respectivo ano anterior. Dessa maneira, em termos reais, a despesa primária se estagnaria, congelando-se no valor real do seu primeiro ano de vigência (2016). No específico caso do financiamento da saúde, vigoraria o percentual estipulado pela Emenda Constitucional $\mathrm{n}^{\circ} 86$, de 2015 , equivalente a $15 \%$ (quinze por cento) da receita corrente líquida $^{20}$ (VIEIRA; BENEVIDES, 2016; SANTOS; FUNCIA, 2019).

Segundo estimativa de Vieira e Benevides (2016), a EC 95/2016, proposta pelo poder Executivo e aprovada pelo Congresso Nacional, retirará do SUS em torno de R\$ 400 bilhões de reais em 20 anos, caso seja considerado o crescimento anual do Produto Interno Bruto - PIB a 2,0\% (dois por cento) e a taxa de variação do Índice Nacional de Preços ao Consumidor Amplo (IPCA) em 4,5\% (quatro e meio por cento).

O mínimo de investimento na saúde seria de $12 \%$ (doze por cento) da Receita Corrente Líquida dez anos depois da aprovação da EC 95/2016, ou seja, em 2026, e de 9,4\% (nove vírgula quatro por cento) no último exercício financeiro de 2036. Índices bem abaixo, portanto, dos $15 \%$ (quinze por cento) estipulados pela EC 86/2015, que serviria de parâmetro para o escalonamento da EC 95/2016.

Pinto e Ximenes (2018) compreende que a EC 95/2016, implementadora de um Novo Regime Fiscal (NRF), trata-se, na verdade, de uma repetição - em maior ou menor grau - da Lei de Responsabilidade Fiscal $(\mathrm{LRF})^{21}$, pois obriga obediência ao teto de despesas primárias, incluindo aqui as despesas obrigatórias e excluindo as despesas financeiras. A EC/95 traria uma inovação, no entanto, no que diz respeito ao período de duas décadas de obrigação do congelamento dos gastos, "ao invés da meta de resultado primário orientadora dos contingenciamentos de despesas discricionárias, prática de política econômica adotada há décadas pelos diferentes governos da União" (PINTO; XIMENES, 2018, p. 992). Nesse sentido, a EC 95 também pode ser classificada como um dos elementos da crise do presidencialismo de coalizão por interferir (in)diretamente nas próximas legislaturas. 
${ }^{20}$ Os $15 \%$ da receita corrente líquida (RCL) investidos pela União e vigentes desde a aprovação da EC 86/2015 são utilizados como parâmetro para o congelamento de gastos durante os vinte exercícios financeiros propostos. A aprovação da EC 86/2015 foi um retrocesso se comparado com a proposta elencada pelo movimento Saúde +10 que lutava por uma aplicação pela União de $10 \%$ da receita corrente bruta (RCB). Retrocesso pois os $15 \%$ da RCL vigentes pela EC 86 equivalem hoje a cerca de R\$117,3 bilhões e, caso fossem investidos $10 \%$ da RCB, equivaleriam a aproximadamente R\$ 142 bilhões, ou seja, um acréscimo de mais de R $\$ 20$ bilhões. Sem contar que a participação das transferências do SUS pela União vem caindo ano a ano: de 4,3\% da receita líquida em 2010 para 2,5\% em 2019. Disponível em: http://www.tesouro.fazenda.gov.br/documents/10180/352657/RRSfev2019.pdf. Acesso em: 12 jul. 2021. Disponível em: https://www2.camara.leg.br/camaranoticias/noticias/SAUDE/498269-RELATORAPROPOE-PISO-PARA-SAUDE-EM-19,4-DA-RECEITA-CORRENTE-LIQUIDA-EM-SEIS-

ANOS.html. Acesso em: 12 jul. 2021.

${ }^{21}$ Lei Complementar $\mathrm{n}^{\circ}$ 101, de 04 de maio de 2000, que "Estabelece normas de finanças públicas voltadas para a responsabilidade na gestão fiscal e dá outras providências". Disponível em: http://www.planalto.gov.br/ccivil_03/leis/lcp/lcp101.htm. Acesso em: 12 jul. 2021.

Pinto e Ximenes (2018), que denomina a EC 95/2016 de "Emenda (In)Constitucional”, assinala o impacto orçamentário da medida no financiamento da política pública de saúde no Brasil - Ações e Serviços de Políticas de Saúde (ASPS) - ao comparar a ausência de eficácia do art. 55 do ADCT da Constituição, que estipulou em vão um investimento de 30\% (trinta por cento) do Orçamento da Seguridade Social (OSS) em saúde que, desde 1988, nunca foi aplicado e, atualmente, a aprovação do art. 110 do ADCT - implementado pela EC 95/2016, que congela o gasto em saúde.

Segundo as mesmas autoras, caso o art. 55 do ADCT estivesse em vigor, no ano de 2018 teria sido investido em ASPS o montante de R 217 bilhões, correspondentes aos $30 \%$ (trinta por cento) do OSS, contra os R 117 bilhões previstos para o ano de 2019, estipulado pela EC 95/2016. Ou seja, uma perda de investimento na casa dos R\$ 100 bilhões, um dado que sintetiza a alteração do patamar de subfinanciamento para a situação de desfinanciamento da política pública de saúde no Brasil.

Pinto e Ximenes (2018) destaca que a norma constitucional do Inc. I do $\S 2^{\circ}$ do art. $198^{22}$ não foi alterada ou revogada, portanto, segue vigente, porém sem produzir efeitos jurídicos e, consequentemente, perdendo sua eficácia até o último exercício financeiro de vigência da EC/95 em 2036. Cenário esse que conduz a uma diminuição da porcentagem de investimento mínimo estipulada pela Constituição, explicitando uma verdadeira "crise desconstituinte" (PAIXÃO, 2018) em que os Direitos Econômicos, Sociais e Culturais (DESC) estão submersos em um denominado "estado de sítio físcal" (PINTO; BIASOTO JUNIOR, 2016).

Albert (2018) classifica o fenômeno da aprovação de Emendas Constitucionais contrárias aos direitos sociais pelo Congresso Nacional, tais como a EC 95/2016, como desmembramento constitucional, processo pelo qual, por meio do poder de reforma 
constitucional, as instituições políticas alteram significativamente a identidade originária de uma Constituição, produzindo alterações radicais em sua natureza normativa. Conforme explicita o autor mencionado:

22 Art. 198. As ações e serviços públicos de saúde integram uma rede regionalizada e hierarquizada e constituem um sistema único, organizado de acordo com as seguintes diretrizes:

(...)

$\S 2^{\circ}$ A União, os Estados, o Distrito Federal e os Municípios aplicarão, anualmente, em ações e serviços públicos de saúde recursos mínimos derivados da aplicação de percentuais calculados sobre: (Incluído pela Emenda Constitucional n ${ }^{\text {2 } 29, ~ d e ~ 2000) ~}$

I - no caso da União, a receita corrente líquida do respectivo exercício financeiro, não podendo ser inferior a 15\% (quinze por cento) (Redação dada pela Emenda Constitucional n ${ }^{\circ} 86$, de 2015).

Algumas emendas constitucionais não são emendas, em absoluto. Elas são esforços autoconscientes para repudiar as características essenciais da Constituição e destruir suas fundações. Elas desmantelam as estruturas básicas da Constituição enquanto, ao mesmo tempo, fundam uma nova baseada em princípios contrários aos da antiga. Essas mudanças constitucionais geram consequências para todo o direito e sociedade (ALBERT, 2018, p. 3, grifo nosso).

Constatamos que a política pública de saúde brasileira foi mantida desde sempre em uma condição de subfinanciamento crônico e, atualmente, com a vigência da EC 95/2016, declinou para uma fase de desfinanciamento contínuo, ratificando, dessa forma, o "descompromisso com os direitos de cidadania combinado com o desmonte do SUS evidenciado em aspectos recentes da política de saúde e da execução orçamentária e financeira do Ministério da Saúde” (FUNCIA, 2018, p. 96). Tal cenário coloca em risco as tarefas do Sistema de Saúde para os desafios do futuro, como o preparo para atuação em pandemias e em pós-pandemias (sequelas), as mudanças no quadro demográfico e epidemiológico e o constante aumento das arboviroses, comprometendo o quadro sanitário de nossa população.

\section{Considerações Finais}

Constatamos que o histórico-normativo do financiamento do direito à saúde no Brasil não chegou a desfrutar de uma estabilidade orçamentária a ponto de efetivar os princípios, objetivos e diretrizes do Sistema Único de Saúde (SUS), conforme preconizado pela nossa Constituição Federal.

Vimos que o direito à saúde passou de um contexto de subfinanciamento para 
um desalentador quadro de desfinanciamento contínuo e estrutural, principalmente com a aprovação e vigência da denominada "Emenda do Teto dos Gastos" - EC n 95, de 2016, que durará longos vinte exercícios financeiros.

Tal situação fomenta um sistema de saúde disfuncional e precário, inviabilizando seu caráter de universalidade, integralidade e equidade, comprometendo a efetivação dessa política pública em um país já atingido por uma pandemia trágica com sérias consequências.

Dessa maneira, é preciso uma necessária e urgente reflexão sobre o SUS que queremos, começando pelo debate em torno da revogação da $\mathrm{EC}^{\circ} 95$ a fim de ratificar o projeto civilizatório estruturado por nossa Constituição Cidadã.

\section{Referências}

AFONSO, José Roberto. Financiamento da Saúde no Brasil: os desafios do estado e da sociedade. Apresentação - SAHE South America Health Exhibition, São Paulo, 2018. Disponível em: https://www.joserobertoafonso.com.br/financiamento-da-saudebrasil-afonso/ Acesso em: 12 jul. 2021.

ALBERT, Richard. Constitutional Amendment and Dismemberment. Yale Journal of International Law, v. 48, n.1, p. 1-118, 2018. Disponível em:

https://digitalcommons.law.yale.edu/cgi/viewcontent.cgi?article $=1685 \&$ context $=y j i l$ Acesso em: 12 jul. 2021.

BRASIL. Constituição da República Federativa do Brasil de 1988. Brasília: Senado Federal, 2021.

BRASIL. Emenda Constitucional $\mathbf{n}^{\circ}$ 95, de 15 de dezembro de 2016. Disponível em: http://www.planalto.gov.br/ccivil 03/constituicao/emendas/emc/emc95.htm Acesso em: 12 jul. 2021.

BRASIL. Emenda Constitucional no 29, de 13 de setembro de 2000. Disponível em: http://www.planalto.gov.br/ccivil 03/Constituicao/Emendas/Emc/emc29.htm. Acesso em: 12 jul. 2021.

BRASIL. Supremo Tribunal Federal. STF - Ação Direta de Inconstitucionalidade (ADI) n 5715, de 2017 - Relator: Min. Rosa Weber. Disponível em: http://portal.stf.jus.br/processos/detalhe.asp?incidente=5203351 Acesso em: 12 jul. 2021.

FUNCIA, Francisco R. Sistema Único de Saúde - 30 anos: do subfinanciamento crônico para o processo de desfinanciamento decorrente da emenda constitucional 95/2016. In 30 Anos da Seguridade Social - Avanços e Retrocessos.

ANFIP/Fundação ANFIP de Estudos Tributários e da Seguridade Social. Brasília: 
ANFIP, 2018.Disponível em: https://www.anfip.org.br/publicacoes/30-anos-daseguridade-social-avancos-e-retrocessos/ Acesso em: 12 jul. 2021.

MARQUES, Rosa Maria. Notas Exploratórias sobre as Razões do Subfinanciamento Estrutural do SUS. Planejamento e Políticas Públicas - PPP/IPEA, n. 49, jul./dez. 2017. Disponível em: http://www.ipea.gov.br/ppp/index.php/PPP/article/view/950 Acesso em: 12 jul. 2021.

MARQUES, Rosa Maria; PIOLA, Sérgio Francisco; ROA, Alejandra Carrillo (Org.). Sistema de Saúde no Brasil: organização e financiamento. Rio de Janeiro: ABrES; Brasília: Ministério da Saúde, Departamento de Economia da Saúde, Investimento e Desenvolvimento; OPAS/OMS no Brasil, 2016. Disponível em:

http://bvsms.saude.gov.br/bvs/publicacoes/sistema_saude_brasil_organizacao_financia mento.pdf Acesso em: 12 jul. 2021.

MENDES, Áquilas; FUNCIA, Francisco. O SUS e seu Financiamento. In MARQUES, Rosa Maria; PIOLA, Sérgio Francisco; ROA, Alejandra Carrilo. (Orgs.). Sistema de Saúde no Brasil: organização e financiamento. Rio de Janeiro: ABrES; Brasília:

Ministério da Saúde, Departamento de Economia da Saúde, Investimentos e Desenvolvimento; OPAS/OMS no Brasil, 2016. Disponível em:

http://bvsms.saude.gov.br/bvs/publicacoes/sistema_saude_brasil_organizacao_financia mento.pdf Acesso em: 12 jul. 2021.

MENICUCCI, Telma Maria. A Política de Saúde no Governo Lula. Revista Saúde e Sociedade, V. 20, n.2, São Paulo Abr/Jun. 2011. Disponível em:

http://www.scielo.br/scielo.php?script=sci_arttext\&pid=S0104-12902011000200022 Acesso em: 12 jul. 2021.

OCKÉ-REIS, Carlos Octávio. Sustentabilidade do SUS e renúncia de arrecadação fiscal em saúde. Ciência e Saúde Coletiva, 23 (6): 2035-2042, 2018. Disponível em: http://www.scielo.br/pdf/csc/v23n6/1413-8123-csc-23-06-2035.pdf Acesso em: 12 jul. 2021.

OMS. Constituição da Organização Mundial da Saúde (OMS/WHO). 1946.

Disponível em: http://www.direitoshumanos.usp.br/index.php/OMS-

Organiza\%C3\%A7\%C3\%A3o-Mundial-d+a-Sa\%C3\%BAde/constituicao-daorganizacao-mundial-da-saude-omswho.html. Acesso em: 12 jul. 2021.

PAIXÃO, Cristiano. 30 anos: crise e futuro da Constituição de 1988. Jota, 2018.

Disponível em: Disponível em:

https://www.jota.info/paywall?redirect_to=//www.jota.info/opiniao-eanalise/artigos/30-anos-crise-e-futuro-da-constituicao-de-1988-03052018 Acesso em: 12 jul. 2021.

PINTO, Élida Graziane; BIASOTOJÚNIOR, Geraldo. Suspender ou adiar custeio de direitos fundamentais nem deveria ser cogitado. CONJUR, 2016. Disponível em: https://www.conjur.com.br/2016-jul-03/adiar-custeio-direitos-fundamentaisnemdeveria-cogitado Acesso em: 12 jul. 2021. 
PINTO, Élida Graziane; XIMENES, Salomão Barros. Financiamento dos Direitos Sociais na Constituição de 1988: do "pacto assimétrico" ao "estado de sítio físcal". Educação e Sociedade, Campinas, v. 39, n 145, p. 980-1003, out./dez., 2018. Disponível em: http://www.scielo.br/scielo.php?script=sci_arttext\&pid=S010173302018000400980 Acesso em: 12 jul. 2021.

PIOLA, Sérgio; et al. Financiamento Público da Saúde: uma História à Procura de Rumo. Texto para Discussão/Instituto de Pesquisa Econômica Aplicada. Brasília: Rio de Janeiro: IPEA, 2013. Disponível em:

http://repositorio.ipea.gov.br/bitstream/11058/1580/1/TD 1846.pdf Acesso em: 12 jul. 2021.

ROTHER, Edna Terezinha. Revisão Sistemática x Revisão Narrativa. Acta Paulista de Enfermagem, São Paulo, Vol. 20, n.2. Editorial. abr/jun 2007. Disponível em: http://www.scielo.br/scielo.php?script=sci_arttext\&pid=S010321002007000200001 Acesso em: 12 jul. 2021.

SALVADOR, Evilasio. Fundo Público e Seguridade Social no Brasil. São Paulo: Cortez, 2010.

SANTOS, Lenir; FUNCIA, Francisco. Emenda Constitucional 95 Fere o Núcleo do Direito à Saúde. Rio de Janeiro: Centro de Estudos Estratégicos da Fiocruz, 2019. Disponível em: https://cee.fiocruz.br/?q=Emenda-Constitucional-95-fere-o-nucleoessencial-do-direito-a-saude. Acesso em: 12 jul. 2021.

SERVO, Luciana; et al. Financiamento e Gasto Público de Saúde: Histórico e Tendências. In MELAMED, Clarice; PIOLA, Sérgio (Orgs.). Políticas Públicas e Financiamento Federal do Sistema Único de Saúde. Brasília: IPEA, 2011.

VIANNA, Solon Magalhães. A Seguridade Social e o SUS - Revisitando o Tema. Revista Saúde e Sociedade V. 14, nº1, p. 7-22, Jan/Abr 2005. Disponível em: http://www.scielo.br/pdf/sausoc/v14n1/03.pdf Acesso em: 12 jul. 2021.

VIEIRA, Fabíola Sulpino; BENEVIDES, Rodrigo Pucci de Sá. O Direito à Saúde no Brasil em Tempos de Crise Econômica, Ajuste Fiscal e Reforma Implícita do Estado.Revista de Estudos e Pesquisas sobre as Américas. V10 n.3. Brasília, 2016. 